\title{
Experimental study on nitrogen and nitrogen foam-assisted gravity drainage for enhancing oil recovery
}

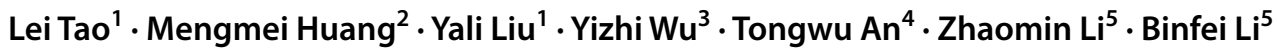

Received: 17 December 2018 / Accepted: 5 March 2019 / Published online: 16 March 2019

(c) The Author(s) 2019

\begin{abstract}
Many factors will affect the result of nitrogen-assisted gravity drainage (NAGD). In this work, sandpack and 2-dimensional (2D) visual plate model were employed to investigate the influence factors of NAGD, such as gas cap volume, formation dip angle, and back pressure. Nitrogen foam was also studied to improve the gas channeling and breakthrough. The experimental results indicated that the gas cap volume was the most significant influence factor on the oil recovery. With the increase of the gas cap volume, the oil recovery increased first and then decreased, and finally increased. The NAGD had a better performance in big dip angle of formation. There was a critical value of back pressure to obtain the maximum oil recovery. However, the gas channeling was intensely observed by experiments of both sandpack and 2D visual plate model. Fortunately, nitrogen foam could effectively inhibit the gas channeling and improve the result of NAGD.
\end{abstract}

Keywords Gas cap volume $\cdot$ Formation dip angle $\cdot$ Nitrogen-assisted gravity drainage $\cdot$ Nitrogen foam

\section{Introduction}

Anticline structure reservoirs, faulted structure reservoir, and buried hill structure reservoirs take a large proportion of the discovered oil reservoirs. Many of them have large angle and thick oil layer, and some of them have bottom water (Ping et al. 2015; Shuxian et al. 2016). Much oil remains in the top of the reservoirs due to the gravity segregation during the development of these reservoirs. It is a challenge to recover the residual oil which is left in the top of the reservoirs with an economical and efficient method.
The gas-assisted gravity drainage (GAGD) process has been used for improving oil recovery in secondary and tertiary modes for both immiscible and miscible processes (Mahmoud and Rao 2008). The process of GAGD is to place a producing well in the lower position of the producing zone and inject gas through the wells located in the reservoir top. Due to the existence of gravity segregation between oil and gas, the gas gets gathered in the top forming the artificial gas cap, results in gravity drainage, which drives the oil and water into the producing well. It could overcome the

\footnotetext{
Binfei Li

libinfei@upc.edu.cn

Lei Tao

taolei2365@163.com

Mengmei Huang

18353248963@163.com

Yali Liu

liuyali17000629@foxmail.com

Yizhi Wu

13954677840@163.com

Tongwu An

antw@keruigroup.com

Zhaomin Li

lizhm@upc.edu.cn
}

1 School of Petroleum Engineering, Changzhou University, Changzhou 213164, Jiangsu, China

2 China National Aviation Fuel Petroleum Fujian Company, Fuzhou 350003, Fujian, China

3 Shengli Oilfield, Sinopec, Dongying 257000, Shandong, China

4 Kerui Petroleum Company, Dongying 257000, Shandong, China

5 College of Petroleum Engineering, China University of Petroleum (East China), Qingdao 266580, Shandong, People's Republic of China 
limitations of the continuous gas injection and the wateralternating-gas, and increase the oil recovery.

The gravity drainage theory was put forward by Cardwell and Parsons (1949). Sharm (2008) and Akhlaghi et al. (2012) conducted 2D visual experiments to simulate the dimensionless parameters used in field projects. They found that the gravity number, the bond number and dimensionless time had great influences on GAGD performance. Catalan et al. (1994), Mahmoud and Rao (2008) and Paidin and Rao (2007) proved the effect of reservoir wettability on oil and gas recovery by experiments. The results indicated that the oil-wet reservoir had higher recovery than water-wet reservoir.

Rostami (2008) studied the impact of displacement rate on gas/oil relative permeability and remaining oil saturation of GAGD process. He believed that higher gas injection rate gave higher gas relative permeability and lower oil relative permeability. A critical gas displacement is existed to obtain the highest remaining oil saturation. Rao et al. (2004) researched the influence of gas injection rate, injection point, and injection mode on the GAGD process. He found that increasing the gas flow rate could get higher oil recovery. Miscible flooding performed a better result than immiscible flooding and injection location had no effect on the ultimate recovery. Ren et al. (2003) conducted the 2D transparent sandpack micro model gravity-assisted tertiary gas injection experiment to compare with the effect of double displacement (DDP) progress and the second contact water displacement (SCWD) progress and performed pore-level observation to investigate the microscopic mechanisms of the two progress. He proved that in DDP, oil flowing through the oil and water was driven not only by its own weight but also by pressure. And SCWD process was suitable for the situation where the remaining gas saturation was high, because remaining gas can reduce the possibility of the residual oil being trapped in the center of the pores so that the residual oil can be recovered quickly by a second water injection.

Although the GAGD can effectively rebuild the formation energy and improve the recovery of oil, the gas channeling is unavoidable during the producing process, especially in heterogeneous formations (Leng et al. 2013; Hart 2014). Farajzadeh et al. (2012) investigated foam improving the gas-oil gravity drainage progress by a numerical method. They found the injected foam could improve gas-oil gravity in the fracture by reducing the gas mobility. Foam can effectively resist in high permeable layer and control gas flow. At the same time, the surfactant in the foam can reduce oil-water interfacial tension, reduce capillary force and improve oil displacement efficiency (Memon et al. 2017; Gandomkar et al. 2012; Åsmund et al. 2014; Fernø et al. 2015).

So far, most of the previous investigations focus on the mechanisms, simulations and applications result of GAGD, few of them research on the specific operating parameters influencing on the oil recovery. And there is only simulation method to research on the nitrogen foam-assisted gravity drainage. To further study the feasibility of nitrogen foamassisted gravity drainage, the $2 \mathrm{D}$ visualization experiment was established.

In this paper, the effects of gas cap volume, formation dip angle, and pressure drop on the oil recovery of NAGD were investigated by sandpack experiments, and the mechanism back of observation was analyzed. Nitrogen foamassisted NAGD was also conducted to investigate the ability to inhibit gas channeling and enhance recovery during the NAGD process. In addition, NAGD process followed by nitrogen foam of which the distribution of remaining oil was observed and the oil recovery was calculated and was carried out through the $2 \mathrm{D}$ visualization plate model.

\section{Experimental section}

\section{Materials}

In the NAGD + nitrogen foam experiment, the crude oil was collected from Shengli Oilfield, China, with a viscosity of $2.8 \mathrm{mPa} \mathrm{s}$ and a density of $920 \mathrm{~kg} / \mathrm{m}^{3}$ at $80{ }^{\circ} \mathrm{C}$. Sodium dodecyl sulfate (SDS) with a purity of $>99.0 \mathrm{wt} \%$ was supplied by Sigma (USA). The concentration of SDS used in the experiment was $0.5 \mathrm{wt} \%$. The nitrogen used in this experiment was provided by Tianyuan Inc. (China), with a purity of $99.9 \mathrm{wt} \%$.

In the visualization experiment, the simulated oil was prepared in proportion of 1:4 with the paraffin oil and the dehydrated crude oil. And the size of silica sand which used to simulate the matrix of 2D visual plate model was 120 mesh, 100 mesh, 70 mesh.

\section{Apparatus}

The apparatus in this study was shown as Fig. 1. The sandpack model had a length of $60.0 \mathrm{~cm}$ and an inner diameter of $2.54 \mathrm{~cm}$. Silica sand with different diameters was used to pack the model to obtain the anticipated permeability and porosities. The crude oil, nitrogen and surfactant solution were placed inside the container. The oil and the surfactant solution were delivered to the sandpack at a constant volumetric flow rate by a piston pump (model 100DX, with flow accuracy $<0.25 \mu \mathrm{L} / \mathrm{min}$ and pressure accuracy $< \pm 0.5 \%)$. A foam generator which was full of silica sand was connected to the upstream of the sandpack. Foam was generated by injecting the surfactant and nitrogen simultaneously through the foam generator. The flow rate of nitrogen was controlled by the gas flow controller 


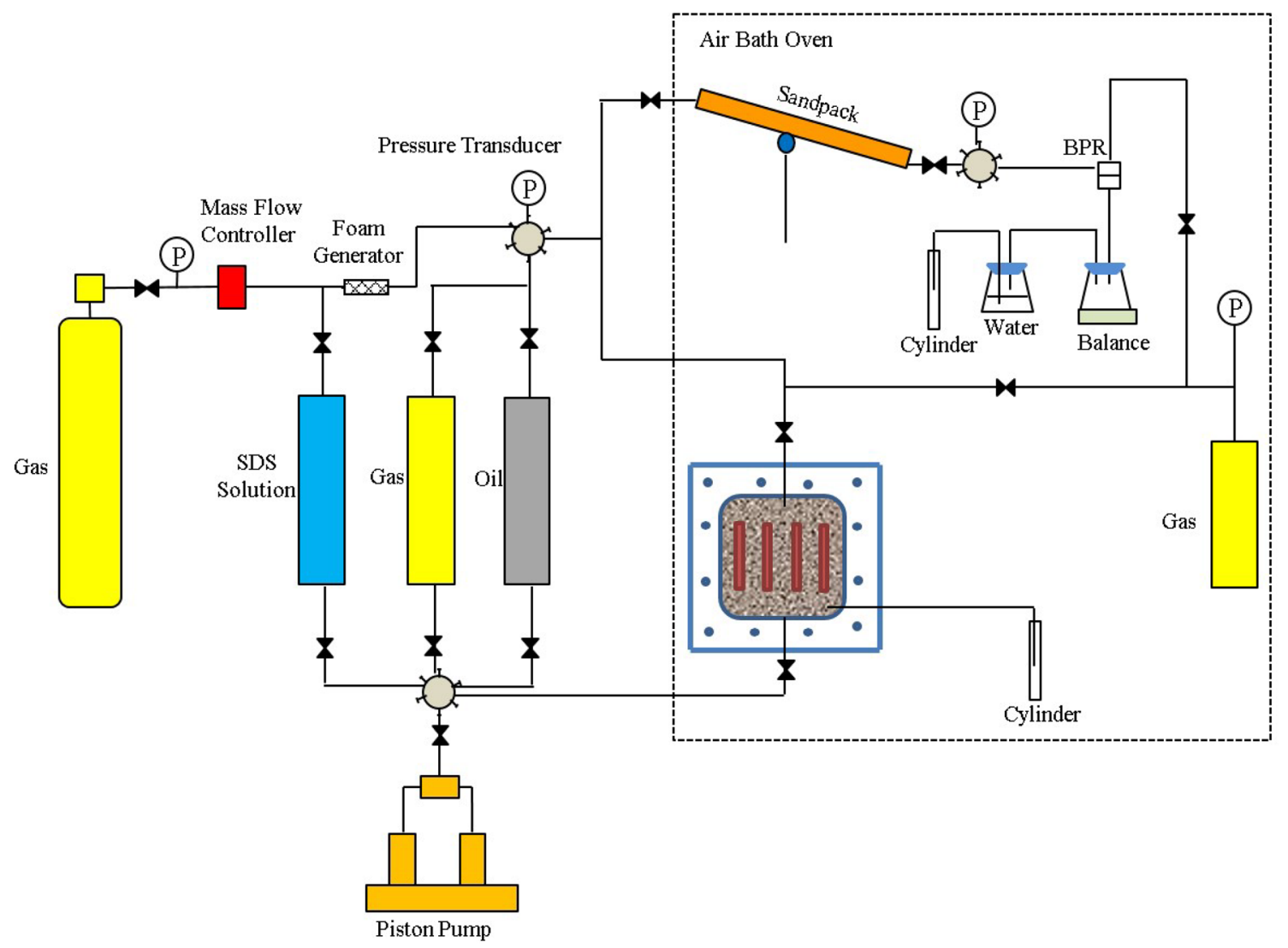

Fig. 1 Schematic of the experimental apparatus

(F-221M, Bronkhorst, accuracy of $0.1 \% \mathrm{fs}$ ). The produced oil and gas were separated by the separator, and they were measured by balance (accuracy $<0.001 \mathrm{~g}$ ) and cylinder (accuracy $<10 \mathrm{ml}$ ) separately. Pressure transducers were used to measure the inlet and outlet pressures of the sandpack during the experiment. A back pressure regulator (BPR) was used to control the outlet pressure of the sandpack with a pressure open error of less than $0.01 \mathrm{MPa}$. The temperature was controlled by an air bath oven to achieve reservoir temperature.

In the visualization experiment, the $2 \mathrm{D}$ visualization plate model was mainly composed of two tempered glass and a metal frame as shown in Fig. 2. As for the tempered glass, the length, width and thickness were $25 \mathrm{~cm}, 25 \mathrm{~cm}$, and $2 \mathrm{~cm}$ separately. First, put two tempered glass into metal frame and install a ring between them for sealing. A space of $25.0 \mathrm{~cm} \times 25.0 \mathrm{~cm} \times 0.6 \mathrm{~cm}$ was left between the two tempered glasses for filling silica sand. The two metal frames with the same size cutting window were then bolted together to fix the glass and a ring was also placed between them to prevent leakage. There had some holes in the edge of metal frame, which connected with the space between two glasses. It can be used to simulate well or sealed with wire plug.

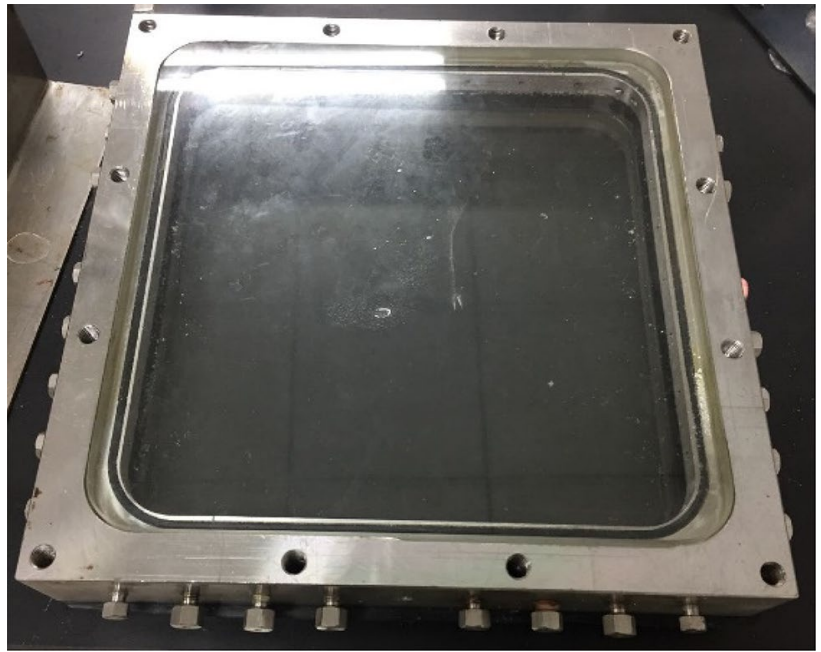

Fig. 2 Two-dimension visualization plate model

\section{Experimental procedure}

\section{NAGD experiments}

The experimental procedures for NAGD were listed as 
follows: (1) silica sand with the same size distribution was used to make sure sandpacks with similar permeability. Table 1 listed some key parameters of sandpack models. Each was evacuated for $4 \mathrm{~h}$ before saturated by distilled water, and the permeability and porosities were measured. (2) Oil was injected into the sandpack with a constant rate of $0.5 \mathrm{ml} / \mathrm{min}$ until there was oil produced at the outlet. The initial oil saturation and remaining water saturation were calculated. (3) The sandpack was controlled to have an inclination $\left(15^{\circ}\right)$ to simulate the dip angle, and heated to the reservoir temperature $\left(80^{\circ} \mathrm{C}\right)$ for $24 \mathrm{~h}$. The back pressure was set to $6 \mathrm{MPa}$ which was consistent with the gas cap pressure. The intermediate cylinder filled with nitrogen was used to simulate the gas cap. (4) The back pressure was gradually reduced and the oil and gas productions were recorded until the pressure at the outlet as low as atmospheric pressure.

\section{NAGD + nitrogen foam experiments}

The first three steps were the same as the NAGD experiments. The methods of NAGD + nitrogen foam were as follow: (1) turned on the outlet valve and let the oil produced until gas broke through and almost no oil produced at outlet, and closed the gas switch. (2) The $12.5 \mathrm{ml}$ pre-generated nitrogen foam was injected into the top of the sandpack at the rate of $0.5 \mathrm{ml} / \mathrm{min}$. (3) The outlet valve was opened again, and continued producing until the gas ran out. (4) In addition, a parallel experiment was conducted. The pressure

Table 1 Parameters of sandpack models

\begin{tabular}{lcl}
\hline Model no. & Permeability $\left(\mu \mathrm{m}^{2}\right)$ & $\begin{array}{l}\text { Initial oil } \\
\text { saturation } \\
(\%)\end{array}$ \\
\hline 1 & 994.2 & 82.21 \\
2 & 998.9 & 83.11 \\
3 & 986.7 & 83.13 \\
4 & 990.2 & 82.67 \\
5 & 983.5 & 81.17 \\
6 & 998.9 & 83.11 \\
7 & 997.5 & 80.79 \\
8 & 1007.9 & 83.26 \\
9 & 954.50 & 81.45 \\
10 & 1000.7 & 80.67 \\
11 & 998.9 & 83.11 \\
12 & 969.5 & 79.87 \\
13 & 1002.5 & 80.51 \\
14 & 1009.2 & 84.16 \\
15 & 1007.8 & 82.39 \\
16 & 968.32 & 80.05 \\
17 & 970.58 & 81.41 \\
\hline
\end{tabular}

drop rate was the same as that before the nitrogen foam was injected, and the oil production was recorded.

\section{NAGD + nitrogen foam visualization experiments}

The procedures for NAGD + nitrogen foam visualization experiment were listed as follows: (1) 2D visualization plate model was cleaned with distilled water and anhydrous ethanol to ensure that there was no dirt. The pipeline was installed at the top and bottom center of the metal frame to simulate the injection wells and installed at the bottom of the right side of the model to simulate the production wells. Ensure that the outlet of production wells should be higher than the model to prevent the flow of simulated oil. And all other holes were sealed. (2) Distilled water was added to the washed and dried silica sand with different size. And the mixture was filled into the model to simulate the matrix which had channels with high permeability. After that, the 2D model was sealed and placed on the bracket perpendicularly for $2 \mathrm{~h}$. (3) Water was injected to saturate model from bottom at a rate of $2 \mathrm{ml} / \mathrm{min}$ until the top of the model produced water for $10 \mathrm{~min}$ after the top produced water. (4) The simulated oil was saturated at a rate of $3 \mathrm{ml} / \mathrm{min}$ from the top of model until the water was no longer produced from the bottom of model. The injection and produced time were recorded to calculate the volume of saturated oil. (5) Nitrogen foam visualization experiment: the intermediate cylinder was injected with nitrogen to simulate the gas cap. The gas cap was controlled to $0.5 \mathrm{MPa}$ and the amount of injection nitrogen was $0.3 \mathrm{PV}$. The simulated gas cap was connected to the top of plate model. Then turned off the value at the bottom of the model and turned on the production value at the right of the model. The outlet pressure was set to be consistent with atmospheric pressure and kept production until there was almost no oil produced. The gas cap pressure, production time and the corresponding oil production were recorded. (6) NAGD + nitrogen foam visualization experiment: the pre-generated nitrogen foam was injected into the model from the top until the oil production was very low and the injection was stopped. In this experiment, the injection rate of sodium dodecyl sulfate (SDS) was $1 \mathrm{ml} / \mathrm{min}$ and the injection rate of nitrogen was $3 \mathrm{ml} / \mathrm{min}$.

\section{Result and discussion}

\section{NAGD experiments}

\section{Effect of gas cap volume on oil recovery}

There is no denying that gas cap volume is a very important factor for NAGD (Mozaffari et al. 2017). In the experiments, the dip angle was controlled to $15^{\circ}$ and the gas cap volume 
was set as 2.5 PV, 2.0 PV, 1.5 PV, 1.0 PV, 0.5 PV, 0.1 PV, and $0.05 \mathrm{PV}$, respectively. Figure 3 shows the relationship between gas cap volume, oil recovery, and gas production. In the figure, the blue line indicates the change of gas production, the black line indicates the change of oil recovery, and the red short line indicates the error involved in the experiments. The error mainly included the gas measurement error caused by the accuracy of the cylinder and the oil measurement error caused by the balance accuracy. The experiment results indicated that oil recovery first increased, second decreased and then increased further.

When the volume of gas cap was low (in Fig. 4a), the amount of gas involved in the oil displacement was less.

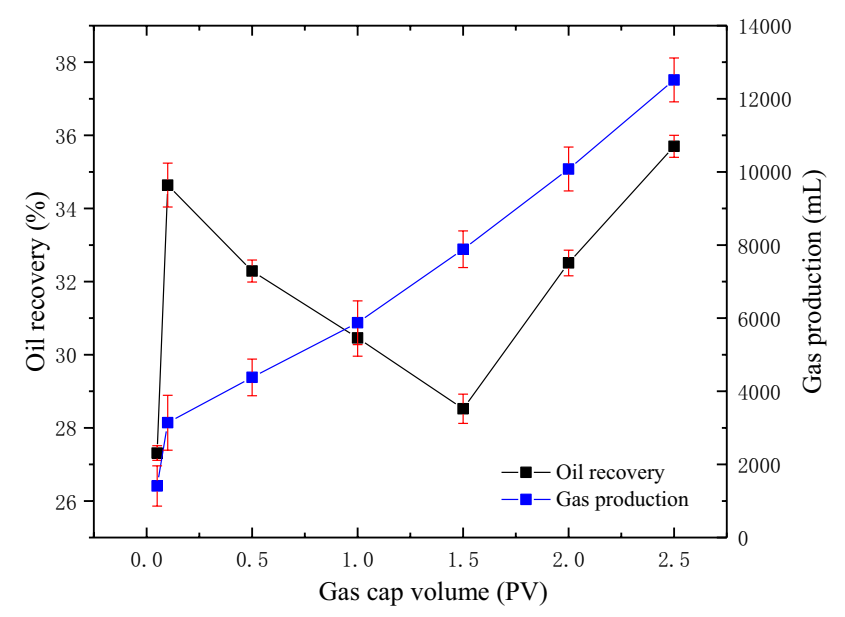

Fig. 3 The influence of gas cap volume on the oil recovery and gas production (experiment condition: temperature $80{ }^{\circ} \mathrm{C}$, formation dip angle $15^{\circ}$, pressure of gas cap $1 \mathrm{MPa}$, back pressure $0.5 \mathrm{MPa}$ )

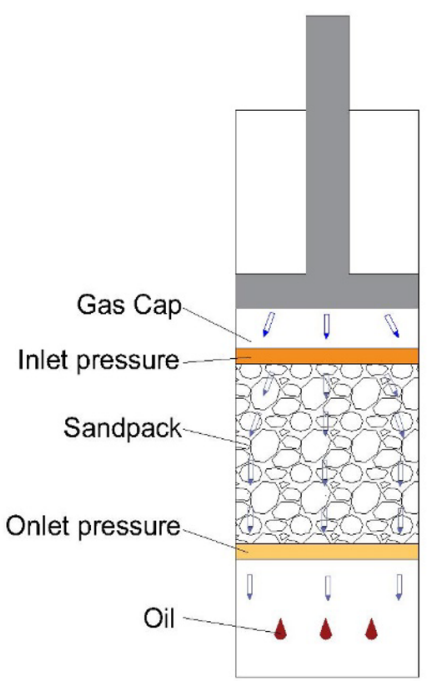

(a)

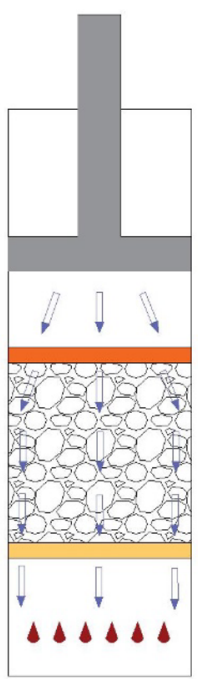

(b)

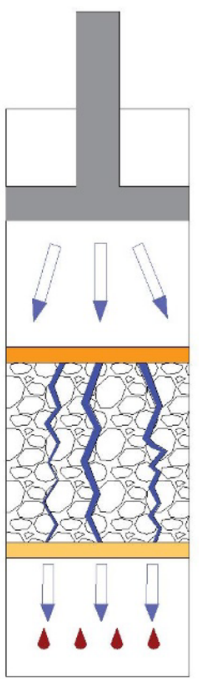

(c)

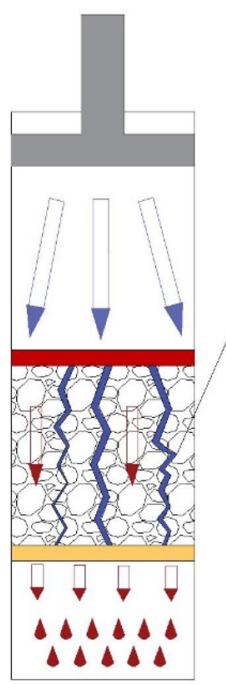

(d)

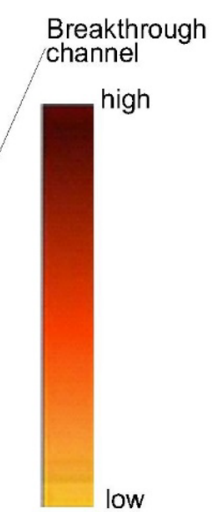

Pressure
Fig. 4 The process of oil recovery changes with gas cap volume strength
The gas relatively steadied stayed on the top of the sandpack and had less elastic energy. Therefore, the possibility of gas breakthrough was limited, and the oil recovery was small. As the gas cap volume slowly increased from 0.05 to 0.1 PV (in Fig. 4b), the amount of gas participated in the oil displacement was improved, and the gas breakthrough became easier to achieve. Thus the high-permeability channels were formed, exploiting a lot of oil which cannot produce before, and the oil recovery was increased. With the gas cap volume increased more, from 0.1 to 1.5 PV (in Fig. 4c), the high-permeability channels formed a comprehensive breakthrough channel, and gas channeling occurred. The gas was discharged through the breakthrough channel and hardly involved in the oil displacement, resulting in the dramatically decreased oil recovery. Continue to increase the volume of gas cap, from 1.5 to 2.5 PV (in Fig. 4d), the gas channeling was more serious. With the increase of gas flow rate, the pressure between inlet and outlet was increased. Thus, the ability of oil displacement and oil recovery was increased.

Therefore, the oil recovery first increased, second decreased and then increased further. The gas production rate increased linearly with the increase of gas cap volume. Considering the economic factors, the volume of the gas cap is preferably $0.1 \mathrm{PV}$.

\section{Effect of formation dip angle on oil recovery}

The formation dip angle was fixed to be $0^{\circ}, 5^{\circ}, 8^{\circ}, 15^{\circ}$, and $20^{\circ}$ in the experiments. Figure 5 shows the relationship of oil recovery and gas production with dip angle. The oil recovery increased all the time while the gas production slightly
. 


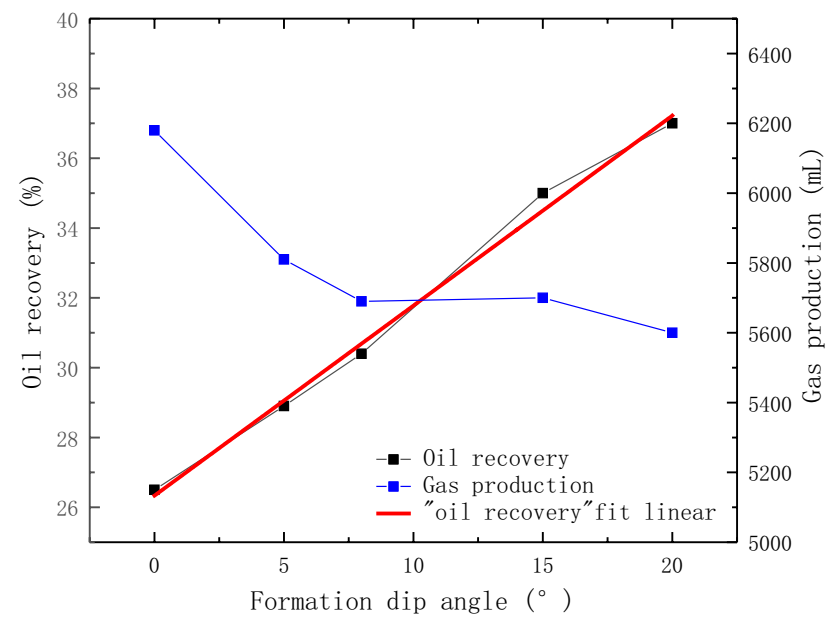

Fig. 5 The influence of formation dip angle on the oil recovery and gas production (experiment condition: temperature $80{ }^{\circ} \mathrm{C}$, gas cap volume $1 \mathrm{PV}$, pressure of gas cap $1 \mathrm{MPa}$, back pressure $0.5 \mathrm{MPa}$ )

decreased with the increase of dip angle. And the decrease velocity of gas production was reduced, when the dip angle up to $8^{\circ}$ and oil recovery at $30-31 \%$.

Due to the gravity separation, the bigger the dip angle, the better the gas cap with low level of gas channeling and the higher oil recovery (Liu et al. 2017). In addition, $\mathrm{N}_{2}$ was easier to overcome the viscous resistance and capillary force to enter a smaller pore throat, which can drive the oil (Darjani et al. 2017). So the oil recovery increased all the time with the increase of dip angle. The reason for the slightly decrease of gas production with the increase of the dip angle is that the larger the dip angle, the greater amount of crude oil was displaced, and the more gas was occupied by pores without producing.

Therefore, to reduce the gas production and increase the oil recovery, the NAGD should be applied to the condition where the dip angle of the formation is greater than $10^{\circ}$.

As shown in Fig. 5, the oil recovery almost linearly increased with the dip angle, and a trend line was added in the Fig. 5. According to the fit linear of the oil recovery with the formation dip angle, the oil recovery at the formation dip angle of $30^{\circ}$ and $40^{\circ}$ can be predicted as $42.66 \%$ and $48.11 \%$.

\section{Effect of back pressure on oil recovery}

The back pressure was, respectively, governed to be 5.7 MPa, 5.5 MPa, 5 MPa, 4 MPa, by controlling the back pressure regulator (BPR). And the dip angle was controlled to $15^{\circ}$, which was studied in the experiments. The influence of back pressure on the oil recovery and gas production was shown in Fig. 6.

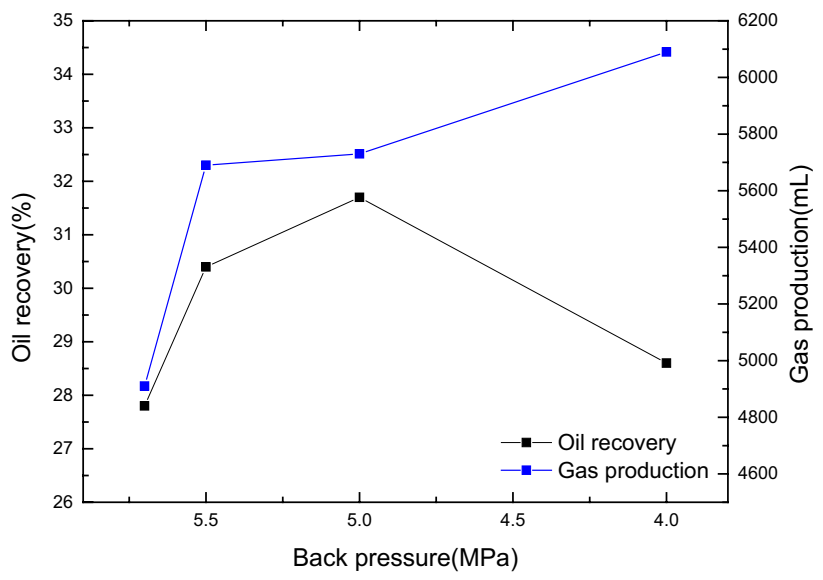

Fig. 6 The influence of back pressure on the oil recovery (experiment condition: temperature $80^{\circ} \mathrm{C}$, gas cap volume $1 \mathrm{PV}$, pressure of gas cap $1 \mathrm{MPa}$, formation dip angle $15^{\circ}$ )

The result indicated that the back pressure has an obvious influence on the oil recovery, and the oil recovery first increased and second decreased with the increase of back pressure. The reason is that, when the back pressure was small, the capacity of gas displace oil was limited and the oil recovery was low. As the pressure increased, the ability of gas drive oil was improved and the oil recovery gradually increased. As the back pressure continues to increase, the gas breakthrough ability was improved and the oil recovery was decreased by the influence of the gas channeling was more and more serious. Therefore, there is a critical value of back pressure in the process of NAGD progress to obtain the best effect of injection gas on the top to drive oil. The gas production rate increased with the increase of back pressure. This is because when the back pressure was small, the energy was insufficient, so the gas cannot be effectively discharged. With the increase of back pressure, the energy increased and the gas production increased accordingly.

The back pressure represented the bottom hole pressure, and the pressure difference between inlet and outlet increased with the decrease of back pressure (Mozaffari et al. 2015). When the back pressure decreased from 5.5 to $5 \mathrm{MPa}$, the pressure difference increased and the gas involved in oil displacement increased. Therefore, the decrease of back pressure promoted oil displacement and the oil recovery increased gradually. When the back pressure decreased from 5 to $4 \mathrm{MPa}$, the pressure difference was too big, which led to serious gas channeling. Therefore, the amount of gas effectively participated in oil displacement was reduced as a result of a decrease on oil recovery. The experiment indicated that there was an optimised back pressure for the maximum recovery during NAGD process. 


\section{Effect of NAGD + nitrogen foam on gas migration and oil recovery during gravity drainage}

To study whether the foam technology can reduce the gas mobility after gas channeling occurs during gravity drive. The injected gas cap volume was $0.5 \mathrm{PV}$ and the pre-generated foam was injected at a constant rate of $0.5 \mathrm{ml} / \mathrm{min}$ for about $25 \mathrm{~min}$ in the experiment.

The influence of NAGD and NAGD + nitrogen foam on the pressure drop cure over time was shown in Fig. 7. In the process of NAGD + nitrogen foam experiment, when the production time was $190 \mathrm{~s}$, foam was injected first, nitrogen was injected second and then the oil was produced. The results shown that, before foam injection, the pressure drop velocity of the two experiments was the same. After injecting the nitrogen foam, the pressure drop rate of NAGD + nitrogen foam was obviously reduced. Through calculation, the average pressure drop rate was $0.33 \mathrm{MPa} /$ min of NAGD and $0.26 \mathrm{MPa} / \mathrm{min}$ of NAGD + nitrogen foam. The average pressure drop rate decreased significantly after the injection of foam.

Figure 8 reveals the change of the oil recovery after injecting the nitrogen foam plugging and pure NAGD. It can be seen that when NAGD was carried out, the recovery of crude oil increased rapidly. With the beginning of gas channeling, the increased rate of oil recovery after NAGD injection quickly dropped down, and the final recovery was $35.51 \%$. As for the nitrogen foam, the foam was injected to the sandpack at $190 \mathrm{~s}$. From then on, the oil recovery was obviously increased, and finally reached to $44.58 \%$, which increased about $9.07 \%$ compared with NAGD. This is because when the gas was injected, the gas mainly moved along the fracture with high permeability, and the sweep

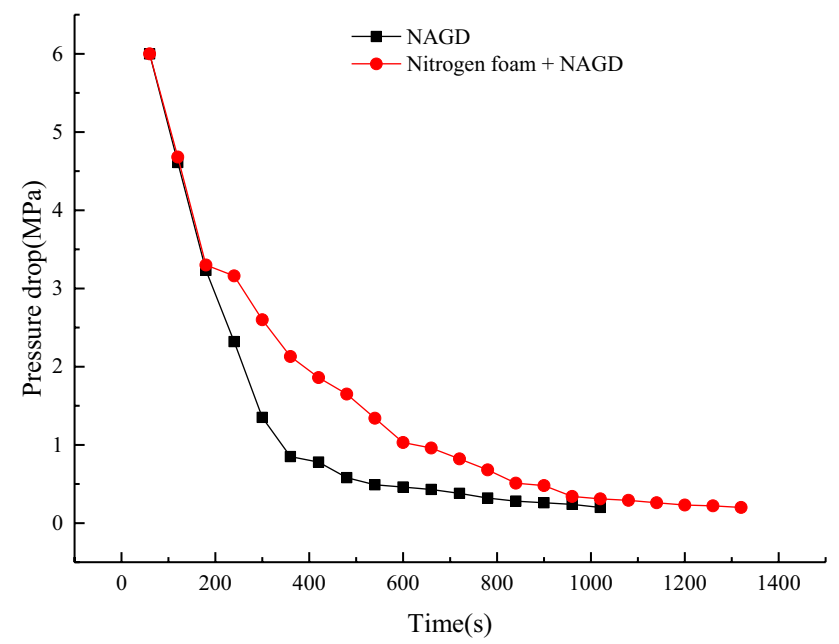

Fig. 7 Pressure drop curve (Experiment condition: temperature $80{ }^{\circ} \mathrm{C}$, gas cap volume $0.5 \mathrm{PV}$, pressure of gas cap $1 \mathrm{MPa}$, formation dip angle $15^{\circ}$, back pressure $0.5 \mathrm{MPa}$ )

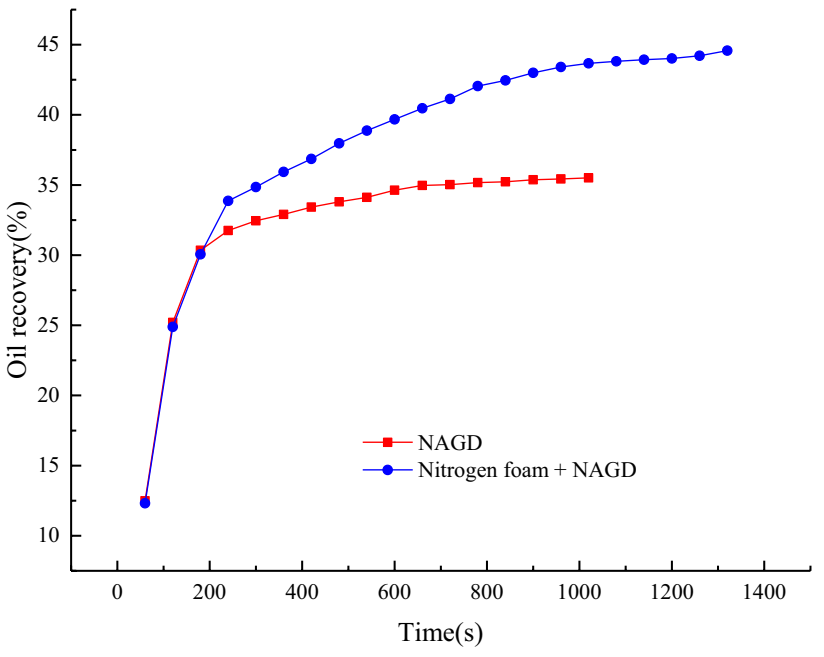

Fig. 8 The different oil recovery between NAGD+NAGD/ nitrogen foam (experiment condition: temperature $80^{\circ} \mathrm{C}$, gas cap volume $0.5 \mathrm{PV}$, pressure of gas cap $1 \mathrm{MPa}$, formation dip angle $15^{\circ}$, back pressure $0.5 \mathrm{MPa}$ )

efficient of the matrix part was small, so it is hard to collect more oil. When the foam was injected, it mainly gathered in the high-permeability channels and enhanced the flow resistance of it. When nitrogen was injected again, it was forced to diffuse around the sandpack so as to increase the sweep coefficient and the oil recovery was increased.

\section{Effect of NAGD + nitrogen foam on oil recovery in the $2 \mathrm{D}$ visualization experiment}

The distribution of remaining oil in the different production stages of NAGD and nitrogen foam-assisted gravity drainage process is shown in Fig. 9. The white area in the figure is the connate water area and the red box is simulated high-permeability channels. The picture captured that when NAGD injected the model, the nitrogen quickly went into channels and drove the oil out. Moreover, the velocity of gas displaced oil in different channels was basically consistent. The gas channeling became very serious at 3 min after NAGD. And NAGD process was ended at $10 \mathrm{~min}$. At this point, most of the oil in the channels had been produced, but there still had some remaining oil in the matrix. There are two stages in the process of NAGD. In the first stage, the single-phase oil was discharged at a high rate and the oil zone in the model was reduced rapidly. The second stage was the production of gas-oil two-phase at a low rate. And after gas channeling, the gas and oil were produced by production wells in the form of alternate slug flow.

After the process of NAGD, the nitrogen foam-assisted gravity drainage was started. The pre-generated nitrogen foam was injected from the top of the model and the oil stored in the matrix was displaced by it. The nitrogen 


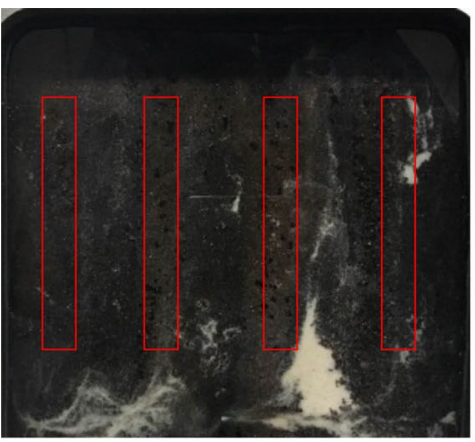

$0 \min$

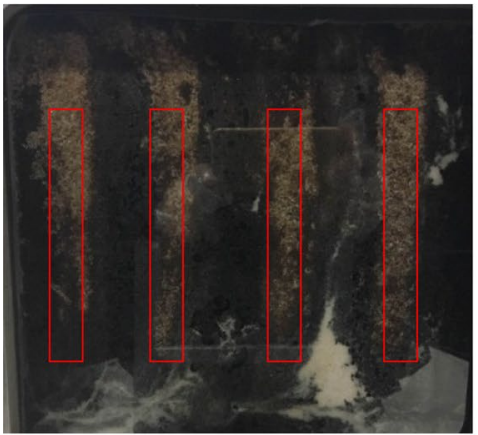

$5 \mathrm{~min}$

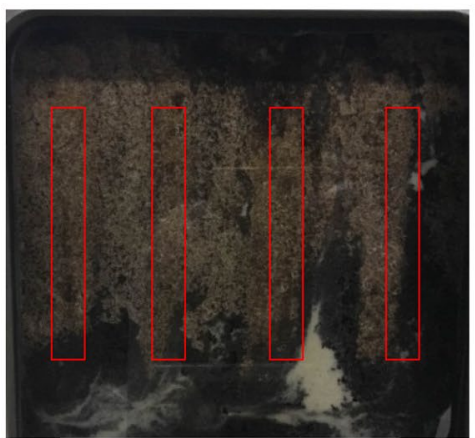

30min

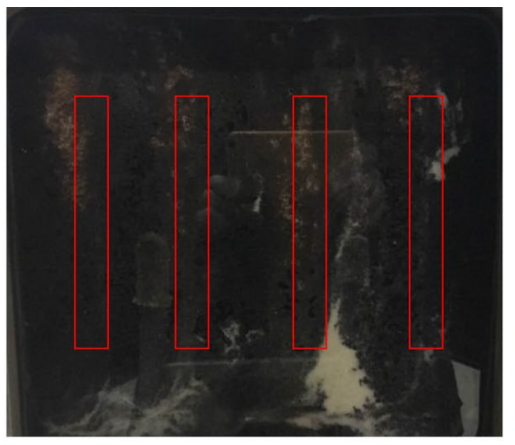

$1 \min$

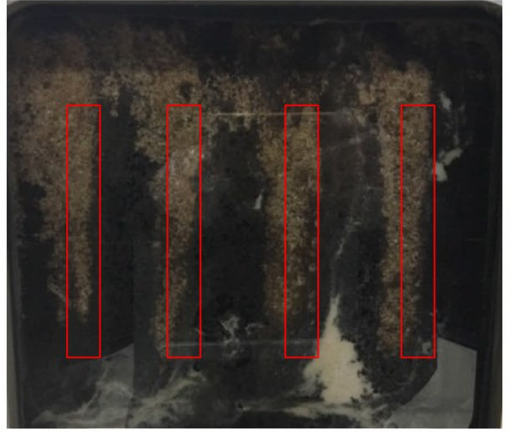

$10 \mathrm{~min}$

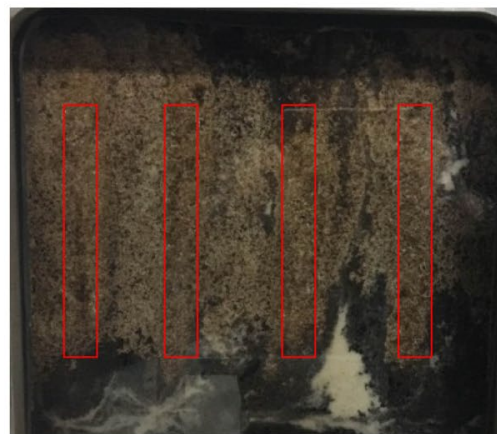

$50 \mathrm{~min}$

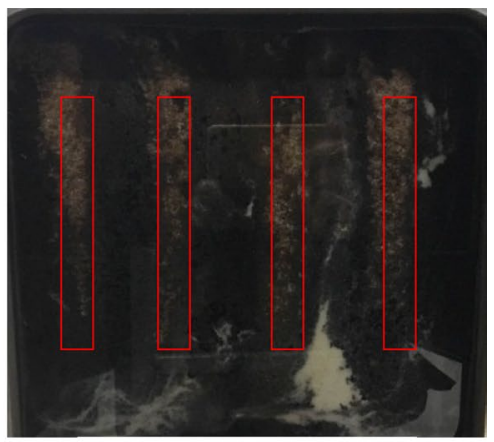

$3 \min$

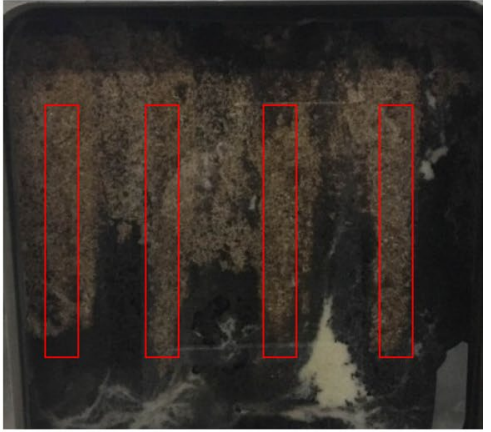

$20 \mathrm{~min}$

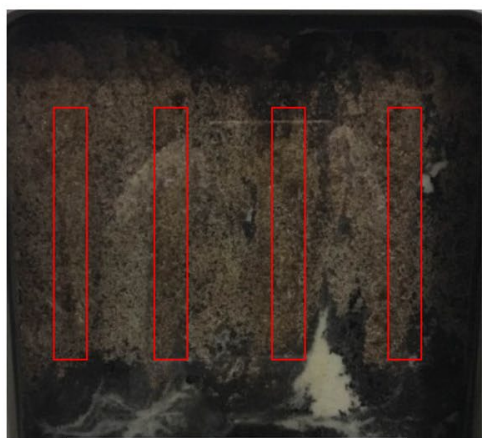

$70 \mathrm{~min}$

Fig. 9 Distribution of remaining oil in the different production processes of nitrogen and nitrogen foam-assisted gravity drainage

foam-assisted gravity drainage process was ended at $7 \mathrm{~min}$ and most of the oil in the model was produced. The reason was that the nitrogen foam first blocked the high-permeability channels, which increased the flow resistance in the channels and the gas channeling was inhibited. As a result, more nitrogen entered low permeability area and the sweep coefficient was increased. At the same time, the foam burst in the matrix and the gas released under the action of gravity segregation moved to the high part of the model. The released gas constantly accumulated and formed the secondary gas cap to displace the top oil and increased the sweep coefficient continuously. What's more, the surfactant in the foam system can reduce the interfacial tension of oil and water greatly and make the connate oil become mobile oil (Samanta et al.
2012; Mozaffari et al. 2016). Thus the efficiency of oil washing was improved. In the end, the interface of remaining oil at the bottom stayed near the production wells.

Figure 10 shows the degree of oil recovery and gas pressure drop rate after nitrogen and nitrogen foam-assisted gravity drainage. The result indicated that the velocity of gas pressure drop was decreased in the process of NAGD and the average pressure drop velocity was $0.05 \mathrm{MPa} / \mathrm{min}$. Therefore, the oil recovery was high and gradually decreased. The final oil recovery was $37.16 \%$. In the process of nitrogen foam-assisted gravity drainage, the pre-generated foam injected from the top of model made the production wells continue to produce oil. Finally, the total oil recovery was $61.01 \%$ and increased $23.85 \%$ compared with NAGD. 
Fig. 10 Oil recovery and pressure drop curve of nitrogen and nitrogen foam-assisted gravity drainage (experiment condition: temperature $80^{\circ} \mathrm{C}$, gas cap volume $0.3 \mathrm{PV}$, pressure of gas cap $0.5 \mathrm{MPa}$, formation dip angle $0^{\circ}$ )

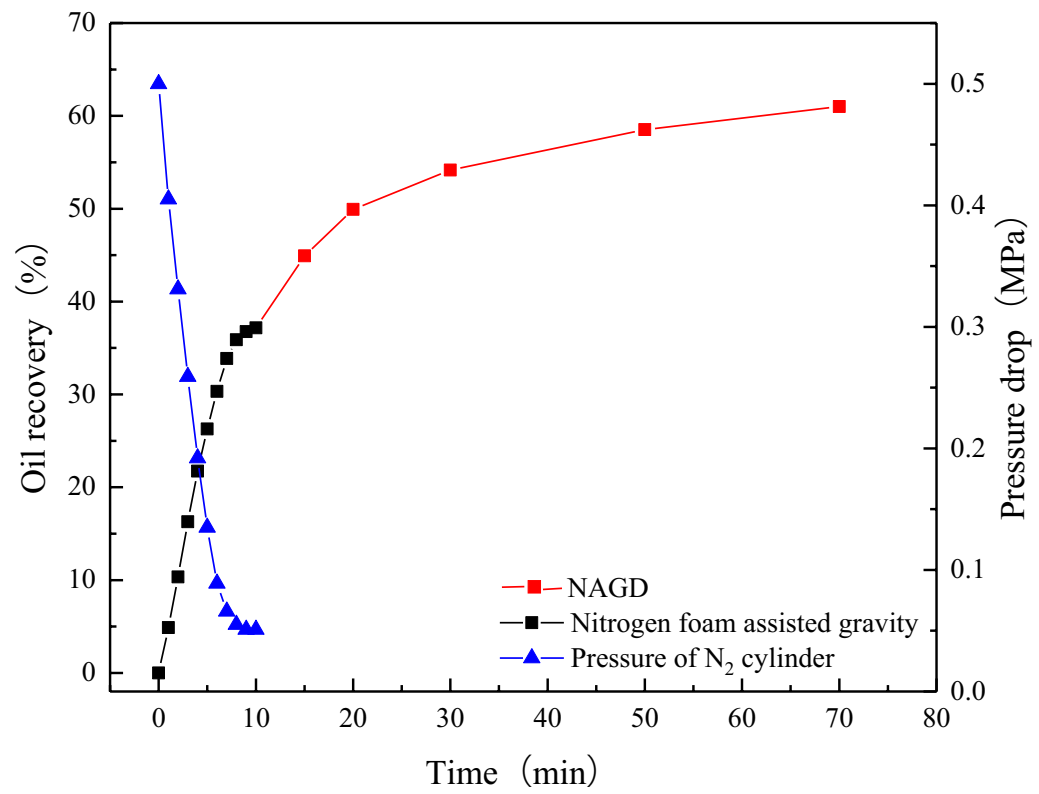

In the NAGD, the nitrogen injected from the top was almost insoluble in oil and gathered to form gas cap under the action of gravity segregation. The oil on the top of model was displaced uniformly and produced through production wells. Since the permeability of the channel was higher than that of the matrix, nitrogen with low viscosity was more likely to flow through the channel and most of oil in the channel was recovered, but some of the oil still remained in the matrix. As for the injection of foam, the foam first entered the high-permeability channels and accumulated continuously to enhance the flow resistance in the channels, which caused more injection gas flow to matrix and expanded sweep efficiency. Meanwhile, the surfactant in the foam system could effectively reduce the adhesion of the oil film and made the oil film easier to flow. Moreover, the foam could emulsify the oil film attached to the sand and carried it out, thus improved the oil washing efficiency.

\section{Conclusion}

The recovery of crude oil can be effectively improved by NAGD. In this paper, the effect of gas cap volume, formation dip angle, and pressure drop rate was studied by means of the sandpack experiments. In addition, the effect of NAGD + nitrogen foam was discussed.

1. With the increase of the gas cap volume, the oil recovery first increased, second decreased and then increased further. The gas production rate increased linearly with the increase of gas cap volume.
2. As the formation dip angle increased, the oil and gas gravity differentiation was enhanced. So the oil recovery was higher.

3. The back pressure also affects the oil recovery. With the increase of the back pressure, the oil recovery increases first and then decreases. There is a critical value for back pressure.

4. The pressure drop rate also affects the oil recovery. With the increase of the pressure drop rate, the oil recovery increases first and then decreases.

5. The nitrogen foam can control the gas channeling and improve the effect of NAGD. After foam injection, the oil production was obviously increased, which increased about $9.07 \%$.

6. In the NAGD + nitrogen foam $2 \mathrm{D}$ visualization experiment, after nitrogen foam injection, the total oil recovery was $61.01 \%$ and increased $23.85 \%$ compared with NAGD. The nitrogen foam can increase the flow resistance in the channels, inhibit gas channeling and enhance the sweep coefficient, while the surfactant in the foam system can reduce the interfacial tension of oil and water greatly, improve the efficiency of oil washing and improve the oil recovery.

Acknowledgements This work was financially supported by the National Science and Technology Major Project of the Ministry of Science and Technology of China (Grant numbers 2016ZX05011004). We sincerely thank other persons in the Foam Fluid Research Center in China University of Petroleum (East China).

Open Access This article is distributed under the terms of the Creative Commons Attribution 4.0 International License (http://creat ivecommons.org/licenses/by/4.0/), which permits unrestricted use, 
distribution, and reproduction in any medium, provided you give appropriate credit to the original author(s) and the source, provide a link to the Creative Commons license, and indicate if changes were made.

\section{References}

Akhlaghi N, Kharrat R, Mahdavi S (2012) Gas assisted gravity drainage by $\mathrm{CO}_{2}$ injection. Energy Sources Part A Recovery Util Environ Eff 34(17):1619-1627

Åsmund H, Mani N, Svenningsen S et al (2014) Miscible and immiscible foam injection for mobility control and EOR in fractured oil-wet carbonate rocks. Transp Porous Media 104(1):109-131

Cardwell WT, Parsons RL (1949) Gravity drainage theory. Trans Aime 179(1):199-215

Catalan LJJ, Dullien FAL, Chatzis I (1994) The effects of wettability and heterogeneities on the recovery of waterflood residual oil with low pressure inert gas injection assisted by gravity drainage. In: Proceeding of the SPE advanced technology series, Ontario, Canada, April 11-13. Paper SPE 23596-PA

Darjani S, Koplik J, Pauchard V (2017) Extracting the equation of state of lattice gases from random sequential adsorption simulations by means of the gibbs adsorption isotherm. Phys Rev E 96(5):052803

Farajzadeh R, Wassing BM, Boerrigter PM (2012) Foam assisted gasoil gravity drainage in naturally-fractured reservoirs. J Pet Sci Eng 94-95(5):112-122

Fern $\varnothing$ MA, Eide $\varnothing$, Steinsbø M et al (2015) Mobility control during $\mathrm{CO}_{2}$ EOR in fractured carbonates using foam: laboratory evaluation and numerical simulations. J Pet Sci Eng 135:442-451

Gandomkar A, Kharrat R, Motealleh M et al (2012) An experimental investigation of foam for gas mobility control in a low-temperature fractured carbonate reservoir. Liq Fuels Technol 30(10):976-985

Hart A (2014) A review of technologies for transporting heavy crude oil and bitumen via pipelines. J Pet Explor Prod Technol 4(3):327-336

Leng Z, Lü W, Ma D et al (2013) Research of enhancing oil recovery mechanism of GAGD using CT scanning method. Acta Petrolei Sinica 34(2):340-345

Liu F, Darjani S, Akhmetkhanova N et al (2017) Mixture effect on the dilatation rheology of asphaltenes-laden interfaces. Langmuir 33(8):1927-1942

Mahmoud T, Rao DN (2008) Range of operability of gas-assisted gravity drainage process. In: Proceeding of the SPE Symposium on
Improved Oil Recovery, Tulsa, Oklahoma, April 20-23. Paper SPE 113474-MS

Memon MK, Shuker MT, Elraies KA (2017) Study of blended surfactants to generate stable foam in presence of crude oil for gas mobility control. J Pet Explor Prod Technol 7(1):77-85

Mozaffari S, Tchoukov P, Atias J et al (2015) Effect of asphaltenes aggregation on rheological properties of diluted athabasca bitumen. Energy Fuels 29(9):5595-5599

Mozaffari S, Tchoukov P, Mozaffari A et al (2016) Capillary driven flow in nanochannels-application to heavy oil rheology studies. Coll Surf A 513:178-187

Mozaffari S, Li W, Thompson C et al (2017) Colloidal nanoparticle size control: experimental and kinetic modeling investigation of the ligand-metal binding role in controlling the nucleation and growth kinetics. Nanoscale 9(36):13772-13785

Paidin WR, Rao DN (2007) Physical model experiments to evaluate the effect of wettability and fractures on the performance of the gas assisted gravity drainage (Gagd) process. In: Proceeding of the international symposium of the society of core analysts, Calgary, Canada, September 10-12, 2007. Paper SCA 2007-48

Ping G, Chen-Jun Z, Jian X (2015) Present state of gas-assisted gravity drainge. Sci Technol Eng 15(5):176-184

Rao DN, Ayirala SC, Kulkarni MM et al (2004) Development of gas assisted gravity drainage (GAGD) process for improved light oil recovery. In: Proceeding of the SPE/DOE symposium on improved oil recovery, Tulsa, Oklahoma, April 17-21. Paper SPE 89357-MS

Ren W, Bentsen R, Cunha LB (2003) Pore-level observation of gravityassisted tertiary gas-injection processes. Spe Reserv Eval Eng 7(3):194-201

Rostami B (2008) Relative permeability and residual saturation in gas-assisted gravity drainage process. In: Proceeding of the international symposium of the society of core analysts, Abu Dhabi, UAE, 29 October-2 November. Paper SCA 2008-11

Samanta A, Bera A, Ojha K et al (2012) Comparative studies on enhanced oil recovery by alkali-surfactant and polymer flooding. J Pet Exp Prod Technol 2(2):67-74

Sharma A, Rao DN (2008) Scaled physical model experiments to characterize the gas-assisted gravity drainage EOR progress. In: Proceeding of the SPE symposium on improved oil recovery, Tulsa, Oklahoma, April 20-23. Paper SPE 113424-MS

Shuxian L, Wei Z, Jidong Z (2016) Investigation on effect application of the technology of crestal gas injection for stable gravity flooding. J Chem Theory Comput 10(12):221-249 